\title{
Hydroa Vacciniforme-Like Lymphoproliferative Disorder
}

National Cancer Institute

\section{Source}

National Cancer Institute. Hydroa Vacciniforme-Like Lymphoproliferative Disorder. NCI Thesaurus. Code C45327.

A rare, EBV-positive cutaneous T-cell lymphoproliferative disorder, composed of CD8 positive cytotoxic T-lymphocytes. It affects children, almost exclusively in Latin America and Asia. Patients present with papulovesicular skin lesions, clinically resembling hydroa vacciniforme, in areas of sun-exposed skin. 